\title{
AÇÃO DE PROMOÇÃO À SAÚdE RELACIONADA AO SONO SAUDÁVEL DE ESTUDANTES E PROFESSORES DURANTE O ENSINO REMOTO
}

\section{Health promotion action related to healthy sleeping of students and teachers during remote education}

\author{
Paula de Lacerda Santos Ribeiro ${ }^{1}$ \\ Emanuela de Souza Gomes dos Santos ${ }^{2}$ \\ Luciene Nascimento de Freitas ${ }^{3}$ \\ Emmanuely Helueny Aguiar de Andrade ${ }^{4}$ \\ Vicente Bessa Neto ${ }^{5}$
}

\begin{abstract}
Resumo: Este artigo apresenta um relato de experiência de atividades de promoção à saúde em alusão à Semana do Sono 2021, promovendo o aprendizado satisfatório por meio de um sono bom. A presente peça apresenta o caminho metodológico utilizado desde o planejamento, com a definição das tecnologias da informação e comunicação, até a realização do evento. A ação contou com a realização de dois webinários com objetivo de refletir sobre a saúde do sono no ensino remoto para discentes e docentes. Com a interação dos participantes constatou-se o envolvimento e interesse na reflexão sobre a necessidade de mudança de comportamento e adoção de hábitos saudáveis. A prática demonstrou a necessidade de mais ações que avaliem e monitorem o sono e outros aspectos relacionados à saúde de professores e estudantes, durante o ensino remoto.
\end{abstract}

Palavras-chave: Tecnologia social. Educação à saúde. Sono.

Abstract: This article presents the experience report in carrying out health promotion activities in allusion to the Sleep Week 2021, promoting satisfactory learning through a good sleep. This piece presents the methodological path used from the planning with the definition of the

\footnotetext{
${ }^{1}$ Doutora em Biodiversidade e Biotecnologia - BIONORTE/AC. Docente de EBTT no Instituto Federal do Acre, Campus Rio Branco, área Segurança do Trabalho. Líder do grupo de pesquisa em Saúde, Qualidade de Vida e Segurança do Trabalho. ORCID: https://orcid.org/0000-0002-3939-7661 E-mail: paula.ribeiro@ifac.edu.br.

2 Doutora em Saúde Coletiva - UFAC/AC. Docente de EBTT no Instituto Federal do Acre, Campus Rio Branco, área Enfermagem do Trabalho. Membro do grupo de pesquisa em Saúde, Qualidade de Vida e Segurança do Trabalho. ORCID: https://orcid.org/0000-0002-8199-1306. E-mail: emanuela.santos@ifac.edu.br

${ }^{3}$ Estudante no curso Técnico em Segurança do Trabalho, Instituto Federal do Acre, Campus Rio Branco. ORCID: https://orcid.org/0000-0002-4428-0126. E-mail: lucienefreitas664@gmail.com

${ }^{4}$ Especialista em Engenharia de Segurança do Trabalho - UNINORTE/AC. Docente de EBTT no Instituto Federal do Acre, Campus Rio Branco, área Segurança do Trabalho. Membro do grupo de pesquisa em Saúde, Qualidade de Vida e Segurança do Trabalho. ORCID: https://orcid.org/0000-0002-6187-3855. E-mail: emmanuely.andrade@ifac.edu.br
}

${ }^{5}$ Mestre em Gestão de Áreas Protegidas na Amazônia - INPA/AM. Docente EBTT no Instituto Federal do Acre, Campus Rio Branco, área Segurança do Trabalho. Membro do grupo de pesquisa em Saúde, Qualidade de Vida e Segurança do Trabalho. ORCID: https://orcid.org/0000-0002-1290-1397. E-mail: vicente.neto@ifac.edu.br 
information and communication technologies until the realization of the event. The action counted on the realization of two webinars with the objective of reflecting on sleep health in remote education for students and teachers. With the interaction of the participants, there was an involvement and interest in reflecting on the need to change behavior and adopt healthy habits. The practice demonstrated the need for more actions to assess and monitor sleep and other aspects related to the teachers and students health, during remote teaching.

Keywords: Social technology. Health education. Sleep.

\section{Introdução}

Com a publicação do Decreto do Governo do Estado do Acre n. 5465, de 13 de março de 2020 (ACRE, 2020), que suspendeu as aulas presenciais em todo território acreano em março de 2020, com a justificativa de enfrentamento à emergência de saúde pública decorrente da doença COVID-19 (Corona Virus Disease), causada pelo coronavírus SARS-CoV-2 (ACRE, 2020), estudantes e professores do Estado do Acre tiveram que se adaptar para dar continuidade às atividades de ensino e de aprendizagem. Todavia, a população acadêmica não esperava que tal medida temporária se estenderia por tantos meses.

Nesse sentido, toda a sociedade precisou se organizar para a retomada das práticas cotidianas. Apesar do retorno de algumas atividades comerciais, muitos feitos laborais passaram a ser realizados por meio da internet, a partir da própria residência do trabalhador, os chamados home offices. Semelhantemente, atividades escolares e acadêmicas foram retomadas a partir do Ensino Remoto Emergencial (ERE), conforme a Portaria n. 343, de 17 de março de 2020, que dispõe sobre a substituição das aulas presenciais por aulas remotas enquanto durar a pandemia da COVID-19 (BRASIL, 2020).

Diante desse novo cenário, chamado por muitos de o "novo normal", grandes desafios foram e ainda são enfrentados. O não acesso à internet, a falta de habilidade no manuseio de plataformas digitais, a dificuldade em conciliar trabalho/estudo com a rotina familiar e em estudar nessa nova modalidade, o ERE, são apenas alguns entraves que certamente podem comprometer o êxito do processo, mas que vêm sendo superados ao longo desta pandemia (HODGES et al., 2020, RODRIGUES, 2020).

Com o fechamento de escolas e o confinamento doméstico, não só o processo de ensinoaprendizagem de estudantes e professores foi afetado. Evidências recentes mostraram que a pandemia da COVID-19 impactou essa população em diversos aspectos relacionados à saúde, dentre eles, o sono (AZIZI et al., 2020; RIISER et al., 2020; CELLINI et al., 2020).

Segundo Cellini et al. (2020), apesar do aumento do tempo na cama constatado no período de pandemia, um sono de pior qualidade foi relatado entre adultos. Tal constatação é preocupante, considerando que o sono desempenha um papel importante na manutenção da saúde, modulação de diversas funções fisiológicas do organismo, qualidade de vida e aprendizagem (PARUTHI et al., 2016; ITANI et al., 2017, CROWLEY et al., 2018).

Nesse sentido, um grupo de docentes da área de segurança do trabalho do Instituto Federal do Acre (IFAC) propôs uma ação educativa, aproveitando o momento de reflexão promovido pela "Semana do Sono", uma campanha criada pela Associação Brasileira do Sono (ABS), que tem como base o evento Dia Mundial do Sono, fomentado pela World Sleep Federation. O Dia Mundial do Sono é uma campanha global que acontece anualmente no mês de março e reúne instituições, pesquisadores, profissionais da saúde e a sociedade em geral para 
dialogar sobre a importância do sono e os impactos dos distúrbios do sono (WORLD SLEEP SOCIETY, 2021).

Para o ano de 2021, devido às condições impostas pela pandemia da COVID-19, a Semana do Sono trouxe o tema "SONO BOM, FUTURO SAUDÁVEL", com foco em atividades voltadas para a população que teve a rotina e, consequentemente, o sono comprometido, como é o caso da população de estudantes e de professores (ABS, 2021).

A proposta do evento, realizado pelos docentes do curso técnico em Segurança do Trabalho, foi levar conhecimento científico para a comunidade acadêmica, informando e educando acerca da importância do sono para a manutenção da saúde, qualidade de vida e favorecimento da aprendizagem, além de motivar os alunos do curso técnico em Segurança do Trabalho do IFAC a considerarem o sono como fator importante para a saúde do trabalhador.

Como forma de alcançar o público e considerando as restrições de contato físico, lançouse mão das Tecnologias de Informação e Comunicação (TIC's), que durante a pandemia, tornaram-se um dos caminhos para que estudantes, professores e comunidade em geral continuassem com os seus processos de estudos e desenvolvimento pessoal. Entende-se por TIC's as formas tecnológicas utilizadas de comunicação e informação e o seu devido processamento (GERMANI et al., 2013).

Por meio das TIC's, existem duas possibilidades de disseminação de informação: as assíncronas (quando não existe interação em tempo real) e síncronas (com interação em tempo real). Neste trabalho foi utilizada a segunda opção, sendo mais especificamente, a troca de informações simultâneas com uso de sala virtual, divulgado como exemplificado no decorrer do texto.

Acredita-se ainda, que o uso dessa tecnologia proporciona espaços para desenvolvimento e possibilidade de construção de conhecimento além da forma tradicional, sendo assim algo imprescindível para perspectiva em ensino (ARAÚJO SOBRINHO; RIVERA, 2021).

Assim, o presente artigo objetiva relatar a experiência na realização de ação de promoção à saúde durante o ensino remoto emergencial junto à comunidade acadêmica a partir do uso de Tecnologias de Informação e Comunicação.

\section{Planejamento}

O planejamento inicial da atividade ocorreu com a definição da temática do evento, que considerou o momento de ensino remoto emergencial e os impactos à saúde impostos pela nova rotina vivida na pandemia. Dentre as inúmeras dimensões de saúde afetadas, nesse contexto, salientou-se a importância do sono, que foi o tema de pesquisa de doutorado de uma das docentes organizadoras do evento, que também é membro da ABS.

Com a definição da temática, estabeleceu-se a duração do evento, sendo definido pelo grupo a duração de dois dias de atividades, com encontros de até duas horas. Em cada dia de evento foi abordado um subtema, direcionado a um público-alvo definido, mas mantendo aberto para a comunidade em geral e simpática à temática (Quadro 1). Essa definição teve o intuito de não sobrecarregar o tempo de exposição aos instrumentos digitais, bem como favorecer a participação dos estudantes e professores, que se encontravam em dias de atividades letivas.

Os temas dos webinários foram proferidos por docentes do IFAC e da Universidade Federal do Acre (UFAC), sendo todos membros da ABS e pesquisadoras da temática sono. 
Quadro 1 - Temáticas do evento

Webinário 1: Sono e aprendizagem no ensino remoto

Público-alvo: estudantes e comunidade em geral.

Webinário 2: $\mathbf{O}$ ensino remoto e o sono do professor

Público-alvo: docentes e comunidade em geral

Fonte: Elaborado pelos autores (2021).

Após a caracterização do evento, definiu-se o tipo de tecnologia digital ou plataforma a ser utilizada para a gestão da atividade e realização das webconferências. Para essa escolha, partiu-se do pressuposto de que a plataforma deveria atender aos seguintes critérios:

a) permitir o cadastro e credenciamento dos participantes;

b) emitir automaticamente os certificados de participação;

c) ser gratuita, livre e aberta à participação da comunidade acadêmica em geral;

d) ser de fácil utilização pelos discentes e docentes internos e externos à instituição proponente.

Atendendo a esses critérios, definiu-se pela utilização do Even3 ${ }^{\circledR}$ (L3 Soluções em Tecnologia LTDA, Brasil), como plataforma de gerenciamento do evento (Figura 1) e o Google Meeting (Alphabet Inc., Estados Unidos) como plataforma de conferência. Agregadas a estas, utilizou-se o Google Formulário (Alphabet Inc., Estados Unidos) para credenciamento dos participantes, o Canva ${ }^{\circledR}$ (Canva Pty Ltd, Austrália) para diagramação das artes e certificados, o YouTube $^{\mathrm{BR}}$ (Alphabet Inc., Estados Unidos) para compartilhamento da atividade gravada e, assim, ampliar a compreensão e acesso aos conteúdos abordados.

Figura 1 - Site de divulgação do evento

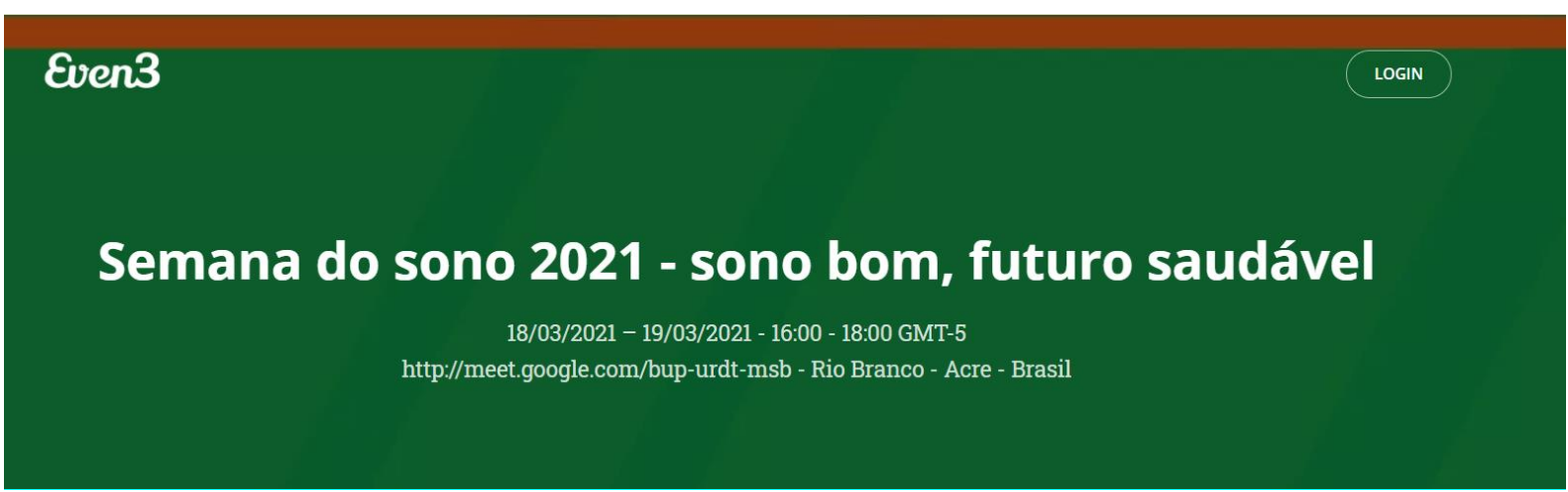

Fonte: Elaborado pelos autores (2021).

Com as plataformas digitais definidas, seguiu-se com a produção de artes, folders, certificados e coleta de informações para a construção da página do evento no Even $3^{\circledR} \mathrm{e}$ posterior divulgação por meio das redes sociais e e-mail. Antes da divulgação, foram feitos testes para identificação de possíveis falhas ou dificuldades no uso da plataforma digital.

O evento foi divulgado digitalmente através do e-mail institucional do IFAC e nas redes sociais do Curso Técnico de Segurança do Trabalho (@crb_tst) de forma a atingir o público a que se destinava: os docentes e discentes dos cinco campi do IFAC (comunidade interna) e de toda comunidade acadêmica externa. 
Com intuito de alcançar o público externo e estabelecer redes de cooperação, o evento foi divulgado entre docentes do Colégio de Aplicação (CAP) da Universidade Federal do Acre (UFAC) e do Centro Universitário UNINORTE.

O evento foi divulgado no site hospedado pelo Even3 ${ }^{\circledR}$ (https://www.even3.com.br/semanadosono2021/), com informações relevantes sobre a ação proposta (Figura 2) e acesso às inscrições, que foram abertas com 10 dias de antecedência. Para proceder com a inscrição, os participantes deveriam preencher o formulário com nome completo, e-mail, categoria de participante (estudante, docente ou outros) e instituição de ensino, em seguida, deveria escolher de qual palestra (webinário) gostaria de participar, sendo facultado a participação em ambas. Por questões de logística, definiu-se o limite de 300 inscritos no evento geral, sem limitação de participantes nas palestras.

Figura 2 - Folder de divulgação do evento

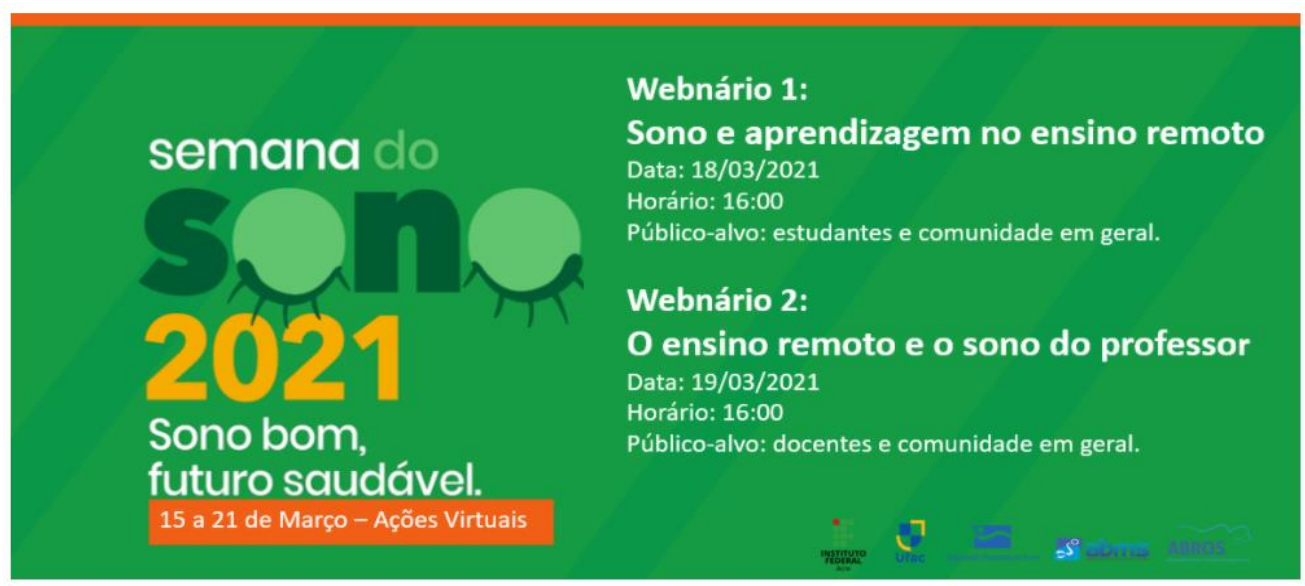

Fonte: Elaborado pelos autores (2021).

Em síntese, o planejamento da ação seguiu as etapas acima descritas e detalhadas no caminho metodológico descrito na Figura 3.

Figura 3 - Caminho metodológico para o desenvolvimento da ação de promoção à saúde

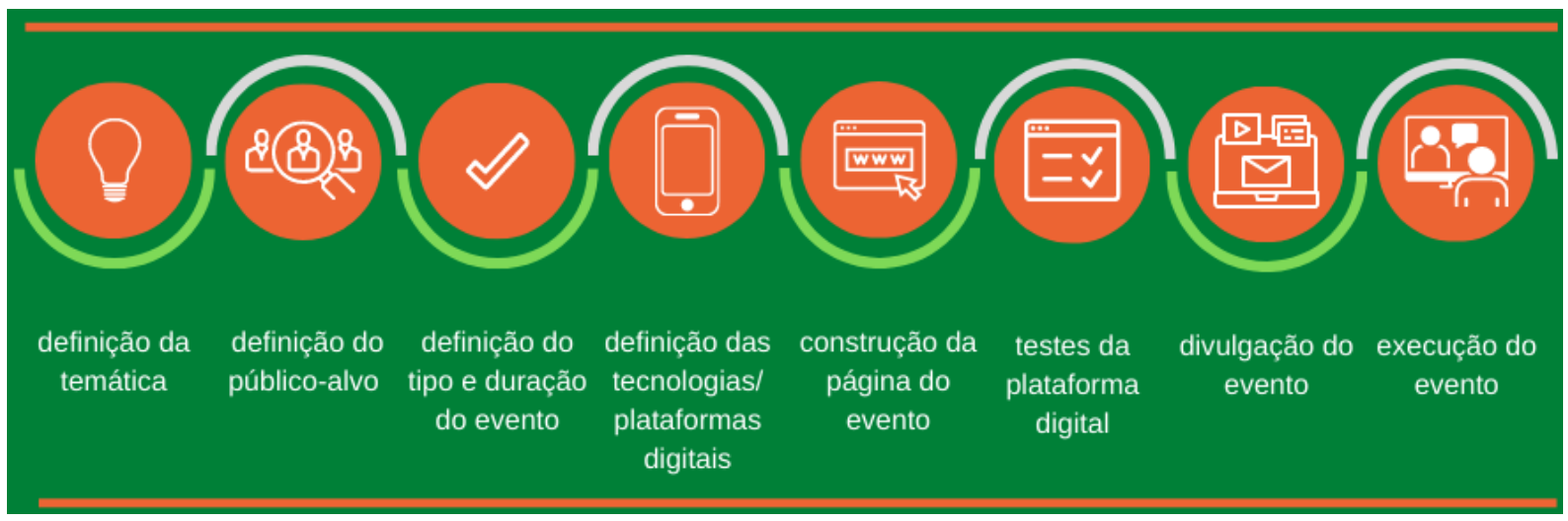

Fonte: Elaborado pelos autores (2021). 


\section{Execução}

O evento Semana do Sono contou com 174 participantes, sendo 4 da comissão organizadora. Destes, $103(59,19 \%)$ participaram do webinário "Sono e aprendizagem no ensino remoto", enquanto 71 (40,81\%) participaram do webinário "O ensino remoto e o sono do professor". Destaca-se que 62 pessoas $(35,63 \%)$ do total de inscritos, participaram de ambos os webinários.

Vale ressaltar que somente a inscrição não garantiu o recebimento do certificado. Para isso, os participantes deveriam participar da ação, confirmando presença durante o evento através do preenchimento do formulário de credenciamento criado no Google Formulário, que contou com duas perguntas, nome do participante e e-mail, e foi disponibilizado durante a realização da palestra no chat do webinário.

O webinário 1 contou com a participação de 103 pessoas credenciadas, sendo 77 (74,75\%) estudantes, $16(15,53 \%)$ docentes, nove $(8,73 \%)$ não informaram, $1(0,97 \%)$ outros. Dentre os 77 estudantes participantes no webinário 1 , observou-se que $62(80,51 \%)$ eram estudantes do CAP ou da UFAC, oito (10,38\%) estudantes do IFAC e sete $(9,09 \%)$ estudantes de outras instituições de ensino.

A expressiva participação dos estudantes do CAP e UFAC pode ser explicada pelo convite estendido a essas instituições de ensino, por meio de contato com docentes que encontraram relevância do tema abordado com o conteúdo e práticas de ensino realizadas em suas respectivas disciplinas. Entendemos que a oportunidade de participar de ações promovidas por outras instituições conferiu aos alunos maior dinamismo no processo de ensinoaprendizagem.

Nesse aspecto, Germani et al. (2013) salientam que o desenvolvimento de práticas participativas é de fundamental relevância para ações de educação em saúde, pois entende-se que pode possibilitar a promoção da saúde da comunidade por meio da disseminação de informação para o desenvolvimento do conhecimento a partir das experiências pessoais desenvolvidas nesses encontros sociais.

Em relação ao envolvimento dos participantes, o primeiro dia de evento foi satisfatório, com participação ativa dos organizadores e inscritos, que em vários momentos expressavam interesse pelo assunto. Os participantes interagiram ativamente pelo chat da plataforma on-line expondo suas dúvidas que podem ser constatadas a seguir:

Professora, quais horários são bons para o nosso aprendizado? (estudante 1, 2021).

E se uma pessoa que dorme tarde e passa a acordar cedo, o que acontece, muda alguma coisa no corpo ou outra coisa? (estudante 2, 2021).

Dormir das 10 da noite até as 6 da manhã é uma quantidade boa para adolescentes? (estudante 3, 2021).

Qual é uma hora boa para se acordar dos 12 anos aos 13 anos? (estudante 4, 2021).

Existem horários mais propícios ao aprendizado ou melhores de alguma forma pra aprender mais? Ou isso é mito ou depende de cada tipo de rotina? (estudante 5, 2021).

Alunos de $\mathrm{EaD}$, que ficam até tarde estudando e passam horas frente ao computador, podem ter a qualidade de sono prejudicada por estarem expostos a luz dos aparelhos eletrônicos e consumindo muitas informações no horário em que já estão com sono e que deveriam estar se preparando para dormir? (estudante 6, 2021). 
Pode-se constatar que o assunto do sono trouxe algumas dúvidas e inquietações por parte dos estudantes ouvintes. Esse fato ocorre, pois o sono é essencial para o bom funcionamento de diversos sistemas do organismo, inclusive na conectividade neuronal, relacionada à consolidação da memória (HUBER; BORN, 2014). Diante da compreensão desse fato biológico, observou-se interesse (estudante 1, estudante 2 e estudante 5) em obter maior aprendizado por meio do sono de qualidade. Quanto ao melhor horário para estudar, foram orientados a observar características pessoais que expressam maior disposição e rendimento, identificando, assim, o seu cronotipo.

Segundo Horne e Östeberg (1976), é possível distinguir os indivíduos em três cronotipos: os matinais ou matutinos, que apresentam preferência pelos horários matinais para realização de tarefas; os tardios ou vespertinos, que apresentam preferência por períodos mais tarde para execução de tarefas; o terceiro tipo são os que não têm preferência por algum horário, intermédios ou indiferentes.

A duração das horas de sono, um questionamento comum e frequente (estudante $3 \mathrm{e}$ estudante 4), foi um aspecto importante e discutido na ação. A duração do sono não é algo absoluto, varia entre os indivíduos e ao longo do ciclo da vida; embora, por explicação biológica, seja comum a diminuição das horas de sono na adolescência (CROWLEY; ACEBO; CARSKADON, 2007). Segundo revisão realizada pelo National Sleep Foundation sobre as horas de sono recomendadas para diversas faixas etárias, nas idades de 6 a 13 anos recomendase de nove a onze horas de sono, e para adolescentes com idade de 14 a 17 anos de oito a dez horas diárias dedicadas ao sono (HIRSHKOWITZ et al., 2015).

Um aspecto relevante abordado foi o uso de dispositivos eletrônicos nesse cenário de ensino remoto ou na modalidade de ensino à distância (estudante 6). Durante o ensino remoto, o uso de dispositivos eletrônicos, além de necessário, pode contribuir de forma positiva para o desenvolvimento de funções cognitivas, inclusive sendo instrumentos importantes para o aprendizado. Entretanto, o uso noturno desses dispositivos merece cuidados na medida que a exposição à luz à noite pode exacerbar a tendência à vespertinidade (DOS SANTOS; DE SOUZA, 2020; BACELAR et al., 2018).

Estudos recentes relatam o uso crescente de celulares por adolescentes no período da noite, antes de dormir. Além de atrasar os ritmos circadianos, a exposição elevada à luz durante à noite aumenta os níveis de alerta e inibe a produção de melatonina (HALE et al., 2018).

Discutir a temática do sono e aprendizagem com os estudantes foi fundamental para esclarecer dúvidas essenciais para a promoção da saúde e melhor aproveitamento escolar/acadêmico. A prática de educação para a saúde mostrou-se relevante, necessária e proveitosa para esse grupo.

No entanto, algumas limitações foram identificadas na execução do webinário um. Alguns inscritos foram impedidos de entrar na sala virtual do Google Meet, tendo em vista que a plataforma digital limitou o acesso de novos participantes a partir do momento que a sala atingiu o número de 100 pessoas. Esse fato observado não havia sido previsto pela equipe organizadora, que desconhecia a política atual da plataforma quanto ao limite de participação máxima de 100 pessoas on-line. Considerando o ocorrido e buscando a universalidade da informação, a organização do evento optou por disponibilizar a gravação do webinário no canal do YouTube ${ }^{B R}$ mantido pela coordenação do curso técnico em segurança do trabalho do IFAC, possibilitando aos estudantes e comunidade em geral o acesso por diversas vezes, o que não é possível, em eventos presenciais (ARAÚJO SOBRINHO; RIVERA, 2021). 
O segundo dia de webinário teve como foco principal o sono do professor. Nesse dia, registrou-se a participação de 71 pessoas, categorizadas em 54 (76,04\%) estudantes, $12(16,9 \%)$ docentes, quatro $(5,63 \%)$ não informaram, um $(1,4 \%)$ outros.

Mesmo com temática voltada para o sono e a rotina de trabalho do professor, observouse que a adesão dos docentes $(16,9 \%)$ foi menor que a adesão dos estudantes. O que tem sido um desafio para a efetividade de ações de promoção à saúde desse grupo profissional. Segundo Couto et al. (2016), para que as ações se concretizem de forma eficiente e permanente, é necessário o comprometimento de todos os envolvidos, propondo o empoderamento da comunidade escolar ou acadêmica acerca da importância de ações dessa natureza.

Os autores ainda destacam que é necessário rever procedimentos metodológicos e de gestão, que incentivem, possibilitem e gerem interesse na participação de ações de promoção à saúde (COUTO et al., 2016). Nesse aspecto, a experiência do evento contou com apoio, incentivo e divulgação por parte da instituição promotora, o que contou positivamente para a execução. No entanto, é necessário estudar outros meios para a aplicação de uma metodologia mais adequada com vistas à uma adesão mais satisfatória.

Sobre a interação dos participantes, destacamos os principais pontos abordados, preservando a identidade dos inscritos.

As mudanças climáticas afetam esses ciclos, prejudicando o sono? A temperatura é função do horário do dia. (participante 1, 2021).

Quais são os principais impactos dos hormônios femininos - durante o ciclo menstrual e a menopausa - no sono? (participante 2, 2021).

Durante a exposição foram destacados aspectos relacionados às alterações fisiológicas que ocorrem no organismo em função do ritmo circadiano, como a diminuição da temperatura (participante 1), frequência cardíaca e até da pressão arterial durante o sono (ITANI et al., 2017). Nesse sentido, destacou-se a necessidade de um ambiente calmo e com temperatura agradável para a indução e manutenção de um bom sono.

Embora o sono não seja responsável pela produção de hormônios, atua como facilitador de sua produção. Portanto, quando os hábitos de sono estão desorganizados, a produção desses hormônios pode sofrer alterações, o que pode implicar na intensificação das manifestações durante a menopausa (ITANI et al., 2017), como abordou o participante 2.

Ao final do evento recebemos o relato de uma professora acerca de sua percepção sobre os conteúdos abordados durante os dois dias do evento, o qual apontou diversos aspectos relevantes para reflexão acerca da promoção da saúde do professor, sobremaneira, no período de pandemia, conforme pode ser observado na transcrição a seguir.

No dia 26 de fevereiro de 2020, com a confirmação do primeiro caso de COVID no Brasil, não imaginávamos o impacto que essa doença teria nas nossas rotinas pessoais e profissionais, e dezesseis dias depois Organização Mundial da Saúde declara a pandemia do novo coronavírus. Como consequência vieram a suspensão das atividades acadêmicas, onde antes já tínhamos uma carga horária semanal excessiva com aulas, planejamentos, atendimentos, reuniões, projetos e demais atividades, a nossa modalidade de ensino mudou e tivemos que nos adaptar ampliando ainda mais a sensação de angústia e a falta de tempo de qualidade para se dedicar às atividades profissionais e pessoais. 
Inicialmente a ansiedade em poder dar continuidade a um ritmo de trabalho que tínhamos antes foi dominando o dia a dia, e vendo que o tempo dedicado às atividades profissionais estavam reduzidos, o horário de trabalho acabou se modificando. $\mathrm{O}$ planejamento de aulas e correções de atividades passaram a ser feitas em horários noturnos, muitas vezes indo até o início da madrugada.

O sono foi afetado, pois o tempo foi diminuído para que fosse possível atender as demandas diárias de casa, filho e aulas. A higiene do sono que antes era possível realizar quase que fielmente, acabou se tornando uma tarefa árdua. Por isso o tema da Semana do Sono 2021 foi muito pertinente, sendo muito assertivo com o seu tema do webinário 2: O ensino remoto e o sono do professor.

Os apontamentos foram excelentes, desde a explicação do ciclo circadiano até a higiene do sono, e foi angustiante ver que clarividente estamos fazendo uma rotina equivocada, prejudicando a nossa saúde física e mental, porém não temos como modificar no momento. Com uma jornada exaustiva e triplicada, a noite se tornou um período aliado de silêncio e calmaria, onde estudamos e trabalhamos nesses horários para poder termos um rendimento parecido ao que tínhamos há um ano atrás. O sono foi o sacrifício que tivemos que fazer para corresponder ou atender o mínimo das expectativas possíveis. Acordamos cansados, para ser sinceros acordamos exaustos, da carga horária de trabalho noturna, das poucas horas de sono dormidas e ainda por cima atender as demandas caseiras e familiares. Na palestra foi muito falado a relação do uso contínuo e o tempo de telas, mas como um professor em ensino remoto vai exercer o seu trabalho sem elas? As telas se tornaram o quadro branco do professor, o celular se tornou a conversa e tira-dúvidas do corredor, e o período da noite se tornou, para muitos, o tempo de planejamento de aulas. A relação professor com as telas e o sono se tornou irresoluta, onde ele precisa diminuir o tempo de um para aumentar o tempo do outro e simplesmente não consegue, porque se o fizer, o professor não executará minimamente o seu trabalho. (participante 3, 2021).

Dado o exposto no depoimento, a pandemia trouxe consigo a necessidade do trabalho remoto docente, e a exigência do nível de qualidade e a atenção com as demandas acadêmicas não diminuíram. Não houve tempo para adaptar o horário de trabalho ao novo ritmo e rotina a que estavam expostos. Muitos docentes passaram por reuniões e formações sem nem ao menos conhecer a realidade à qual os estudantes estavam expostos. O fato do "estar em casa" não representou vantagem para o professor, visto que, ele precisou adaptar a rotina de trabalho à rotina familiar, constituída de atividades domésticas e, muitas vezes, acompanhamento de filhos em idade escolar. Dessa maneira, o professor, inserido numa tripla jornada, tem sua saúde física, mental e sono penalizados pelo trabalho.

Os professores, muitas vezes, não conseguem obter a quantidade de sono desejada, devido aos afazeres e dos hábitos que mantêm antes de dormir ou logo ao acordar. No estudo de De Souza; De Sousa; De Azevedo (2012), o horário do trabalho e as atividades extras (preparações de planos de aulas, correções de trabalhos e provas) foram as razões que determinaram os horários de dormir e acordar, demonstrando a influência do trabalho como fator importante na determinação dos horários de sono.

Martins (2020) ressalta que, durante o cenário de ensino remoto, as preocupações e cuidados precisam ser deslocados para o que realmente importa: as condições de trabalho do docente, a qualidade do processo de ensino-aprendizagem, a relevância e o significado dos temas a serem abordados. Por isso, o sono foi abordado nesta ação de promoção à saúde, dado que o ensino remoto pode promover ainda mais a privação do sono em função do cumprimento do trabalho (DELCOR et al., 2004). 


\section{Conclusão}

A experiência de desenvolver essa temática junto ao público de estudantes e professores foi exitosa, dado o envolvimento de outras instituições e o interesse dos participantes em aprender como desenvolver hábitos de higiene do sono com vistas a uma melhor qualidade de vida e melhor aprendizado. Portanto, considerou-se que o objetivo da ação foi alcançado, pois levou o público-alvo à reflexão da importância da temática, evidenciada pela constante interação e feedbacks referidos por áudio e pelo chat durante os webinários.

As reflexões apresentadas demonstraram interesse na mudança de comportamento e adoção de hábitos saudáveis, considerando a importância fisiológica do sono bom para o bem estar cotidiano e saúde do indivíduo. Ainda, a ação promoveu a percepção do protagonismo do sujeito em suas ações e comportamento na promoção de um sono de maior qualidade, respeitando suas características individuais e a própria biologia em prol da sua saúde.

No que tange aos métodos utilizados, constatou-se a necessidade de estudar novas estratégias para aumentar a adesão dos professores em ações semelhantes que porventura poderão ser realizadas. Ainda, a utilização de tecnologias de informação e comunicação mostrou-se um recurso eficaz para ações de promoção da saúde, sobretudo em tempos de pandemia, demonstrando que seu uso poderá ser utilizado em ações futuras envolvendo outras temáticas.

Por fim, a experiência da realização dos webinários no evento "Semana do Sono" demonstrou a necessidade de mais ações que avaliem e monitorem o sono e outros aspectos relacionados à saúde de professores e estudantes, não só durante o ensino remoto, mas durante sua jornada funcional e acadêmica, visando o bom desempenho e qualidade de vida.

\section{Referências}

ABS, Associação Brasileira do Sono. Semana do Sono 2021: Sono bom, futuro saudável. Disponível em: <https://absono.com.br/>. Acesso em: 10 mar. 2021.

ACRE. Decreto n. 5.465 de 16 de abril de 2020. Dispõe sobre medidas temporárias a serem adotadas, no âmbito do Estado do Acre, para enfrentamento da emergência de saúde pública decorrente da doença COVID-19, causada pelo Coronavírus SARS-CoV-2. Disponível em: <http://www.legis.ac.gov.br/detalhar_covid19/4247>. Acesso em: 12 abr. 2021.

ARAÚJO SOBRINHO, E. M.; RIVERA, J. A. A utilização das TIC's de forma criativa e inovadora no contexto da Educação Profissional e Tecnológica. Revista de Estudos e Pesquisas sobre Ensino Tecnológico (EDUCITEC), v. 7, e110320, 2021.

AZIZI, A. et al. Health-related quality of life and behavior-related lifestyle changes due to the COVID-19 home confinement: dataset from a Moroccan sample. Data Brief, v. 32, p. 106239, 2020.

BACELAR, A. et al. Dossiê: horários escolares e implicações no sono de adolescentes. Associação Brasileira do Sono, 2018. 14 p

BRASIL, Ministério da Educação. Portaria n 343, de 17 de março de 2020. Dispõe sobre a substituição das aulas presenciais por aulas em meios digitais enquanto durar a situação de pandemia do Novo Coronavírus - COVID-19. Disponível em: 
<https://www.in.gov.br/en/web/dou/-/portaria-n-343-de-17-de-marco-de-2020-248564376>. Acesso em: 4 abr. 2021.

CELLINI, N. et al. Changes in sleep pattern, sense of time and digital media use during COVID-19 lockdown in Italy. Journal of Sleep Research, v. 29, n. 4, p. e13074, 2020.

COUTO, A. N. et al. O ambiente escolar e as ações de promoção da saúde. Cinergis, v. 17, 2016.

CROWLEY, S. J.; ACEBO, C.; CARSKADON, M. A. Sleep, circadian rhythms, and delayed phase in adolescence. Sleep Medicine, v. 8, n. 6, p. 602-612, 2007.

CROWLEY, S. J. et al. An update on adolescent sleep: New evidence informing the perfect storm model. Journal of Adolescence, v. 67, p. 55-65, 2018.

DELCOR, N. S. et al. Condições de trabalho e saúde dos professores da rede particular de ensino de Vitória da Conquista, Bahia, Brasil. Caderno de Saúde Pública do Rio de Janeiro, v. 20, n. 1, p. 187-196, 2004.

DE SOUZA, J. C.; DE SOUSA, I. C.; DE AZEVEDO, C. V. M. Conhecimento e hábitos de sono de professores do ensino médio. Disponível em:

$<$ http://abrapecnet.org.br/atas_enpec/viiienpec/resumos/R1174-1.pdf>. Acesso em: 28 mar. 2021.

DOS SANTOS, E.; DE SOUZA, O. F. Association of sleep duration and blood pressure in adolescents: a multicenter study. American Journal of Hypertension, v. 33, n. 1, p. 77-83, 2020.

Even $3^{\circledR}$. Semana do Sono 2021. Disponível em:

<https://www.even3.com.br/semanadosono2021/>. Acesso em: 28 mar. 2021.

GERMANI, A. C. C. G. et al. O uso de tecnologias de informação e comunicação (TIC) em experiências de pós-graduação sobre promoção da saúde no Brasil e na Costa Rica. Revista de Medicina, v. 92, n. 2, p. 97-103, 2013.

HALE, L. et al. Youth screen media habits and sleep: Sleep-friendly screen behavior recommendations for clinicians, educators, and parents. Child and Adolescent Psychiatric Clinics of North America, v. 27, n. 2, p. 229-245, 2018.

HIRSHKOWITZ, M. et al. National Sleep Foundation's sleep time duration recommendations: methodology and results summary. Sleep Health, v. 1, n.1, p. 40-43, 2015.

HODGES, C. et al. The difference between emergency remote teaching and online learning. Educause Review, v. 27, p. 1-12, 2020.

HORNE, J. A.; ÖSTBERG, O. A self-assessment questionnaire to determine morningnesseveningness in human circadian rhythms. International Journal of Chronobiology, v. 4, p. 97-110, 1976. 
HUBER, R.; BORN, J. Sleep, synaptic connectivity, and hippocampal memory during early development. Trends in Cognitive Sciences, v. 18, n. 3, p. 141-152, 2014.

ITANI, O. et al. Short sleep duration and health outcomes: a systematic review, metaanalysis, and meta-regression. Sleep Medicine, v. 32, p. 246-256, 2017.

MARTINS, R. X. A covid-19 e o fim da educação a distância: um ensaio. EmRede: Revista de Educação a Distância, v. 7, n. 1, p. 242-256, 2020.

PARUTHI, S. et al. Consensus statement of the American Academy of sleep medicine on the recommended amount of sleep for healthy children: methodology and discussion. Journal of Clinical Sleep Medicine, v. 12, p. 1549-1561, 2016.

RIISER, K. et al. Adolescents' health literacy, health protective measures, and health-related quality of life during the Covid-19 pandemic. PLoS One, v. 15, n. 18, p. e0238161, 2020.

RODRIGUES, E. Ensino remoto na Educação Superior: desafios e conquistas em tempos de pandemia. SBC Horizontes. Disponível em:

<https://horizontes.sbc.org.br/index.php/2020/06/ensino-remoto-na-educacao-superior/>. Acesso em: 22 ago. de 2020.

WORLD SLEEP SOCIETY, World Sleep Day. Regular Sleep for a Healthy Future, 2021. Disponível em: <https://worldsleepday.org/>. Acesso em: 10 mar. 2021.

Recebido em maio de 2021.

Aprovado em outubro de 2021. 